
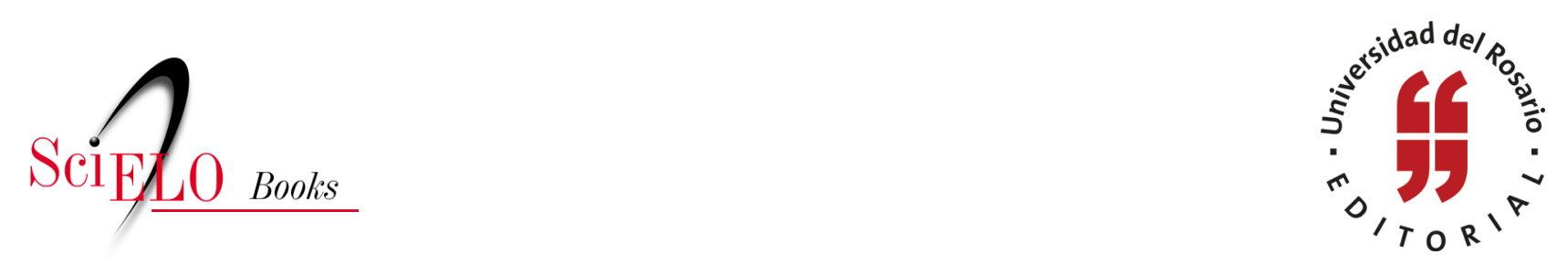

\title{
Aproximaciones a la conformación histórica del territorio de El Codito. \\ Del estatisismo normativo a la construcción social
}

\author{
Juan David Guevara Salamanca
}

\section{SciELO Books / SciELO Livros / SciELO Libros}

SALAMANCA, J.D.G. Aproximaciones a la conformación histórica del territorio de El Codito. Del estatisismo normativo a la construcción social. In: SALAMANCA, J.D.G., GARCÍA, M.H., and MOLINA, M.A.M. Construcción y significación del territorio. Comunidad El Codito, 2011 [online]. Bogotá: Editorial Universidad del Rosario, Instituto Rosarista de Acción Social - SERES, 2013, pp. 56-100. ISBN 978-958-784-206-7. https://doi.org/10.7476/9789587842067.0003.

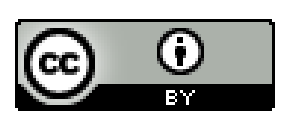

All the contents of this work, except where otherwise noted, is licensed under a Creative Commons Attribution 4.0 International license.

Todo o conteúdo deste trabalho, exceto quando houver ressalva, é publicado sob a licença Creative Commons Atribição $\underline{4.0}$.

Todo el contenido de esta obra, excepto donde se indique lo contrario, está bajo licencia de la licencia Creative Commons $\underline{\text { Reconocimento } 4.0 .}$. 


\title{
Aproximaciones a la conformación histórica del territorio de El Codito. \\ Del estatisismo normativo a la construcción social
}

\author{
Juan David Guevara Salamanca*
}

* Politólogo de la Universidad del Rosario, se desempeñó como coordinador en terreno del proyecto Comunidad y territorio en el sector El Codito. Correo electrónico: juandguevara@gmail. com 
En el norte de Bogotá se erige un conjunto de casas pintorescas, diferenciadas unas de las otras por pequeños detalles, sobre las montañas orientales de la ciudad. Este sector recibe a los visitantes y habitantes de Bogotá que ingresan a la urbe capitalina por el norte de la ciudad y se conoce como el sector El Codito. ${ }^{1}$

A pesar de la aparente homogenización de las construcciones del sector, el proceso histórico de consolidación de este estuvo sujeto a relaciones conflictivas, confrontaciones violentas, regulaciones restrictivas, abandonos estatales y a la continua estigmatización de otros habitantes de la ciudad.

En el marco del presente libro se quiso indagar sobre la consolidación del territorio de El Codito. Este trabajo se enfocó en rehacer la historia del sector, desde sus inicios como haciendas y sitios de explotación de canteras hasta lo que hoy se observa en los cerros nororientales de la ciudad.

Como toda historia contada, este relato puede tener hechos difusos, contradictorios y, para algunos lectores, una historia diferente a la vivida. Por eso se quiere hacer claridad que este escrito obedeció a un trabajo investigativo que tenía como principal finalidad encontrar los elementos comunitarios que permitieron la construcción de los barrios del sector.

Aunque se tiene conocimiento de que El Codito está comprendido por 17 barrios, esta descripción histórica se centra en los barrios más representativos en términos de peso poblacional; por ello, se hace referencia a los barrios Horizontes, Buenavista (sectores I y II), Chaparral y El Codito. Se nombran en algunos casos a los barrios Estrellita Norte y Mirador del Norte como ejemplos concretos de situaciones históricas.

Este capítulo es el resultado de una revisión de la literatura existente sobre la historia de El Codito. El contenido específico sobre este sector fue tomado de escritos hechos por sus habitantes y corroborado a través de entrevistas realizadas a líderes y adultos mayores.

El capítulo se divide en: una primera fase contextual sobre la historia de la localidad de Usaquén; luego, se expone la visión de las autoridades distritales y nacionales sobre los cerros orientales (lugar de asentamiento de los barrios de El Codito), identificando algunas situaciones problemáticas y 
conflictivas sobre la normatividad existente; posteriormente, se detalla el proceso de asentamiento del sector, para cerrar el capítulo con la realidad actual del mismo.

\section{La ciudad y su conformación territorial}

A comienzos del siglo XX, Bogotá compartía las mismas características de las otras ciudades colombianas: no superaba los 100000 habitantes y la conservación arquitectónica de la ciudad colonial permanecía casi intacta, inclusive su perímetro era básicamente el mismo.

Zambrano et al. (2002) destaca que, para comienzos del siglo, la ciudad evidenció un marcado deterioro de las condiciones de vida de sus habitantes, lo que resultó en un descenso notorio de su población total. Así mismo, este evidente decrecimiento poblacional significó el debilitamiento de sus fronteras socio-culturales y elementos de jerarquización, lo que requirió el establecimiento de nuevas fronteras que sirvieran como puntos de diferencia entre los grupos sociales.

Hacia la década de los años veinte del siglo pasado la ciudad empezó un crecimiento desmesurado de población, lo que conllevó la extensión de su perímetro. Según un artículo publicado en el diario El Tiempo, "la población aumentó de 21934 habitantes en 1801 a 100000 en 1905 y a 200000 en 1927 [...] entre 1905 y 1927 Bogotá creció 3,6 veces su tamaño".

En los años treinta, Colombia empieza un proceso de industrialización derivado de la crisis en los países desarrollados y de las transformaciones políticas y sociales de comienzos de siglo. Zambrano et al. (2002) argumenta que este proceso no fue de industrialización sino de modernización derivado de la economía exportadora cafetera, lo que terminó por generar un avance urbano muy específico.

La modernización trajo consigo una serie de elementos que se conjugaron con los valores tradicionales propios de una sociedad y una economía agrarias; ello ha permitido hablar, desde ese entonces, "de una modernidad urbana con fuertes rasgos de sociedad tradicional" (ibídem, p. 221). El resultado de este proceso condujo a que el poder de las clases tradicionales 
no sufriera mayores retos en legitimarse y en manejar la transición modernizadora, sin negociar mayores prebendas ni controles (ibídem).

Bogotá, al ser centro político y económico del país, junto a Cali y Medellín, se volvió un polo de inmigración de personas que provenían de distintas partes de la geografía colombiana en busca de ser empleados como obreros y que buscaban resguardo y seguridad de la primera oleada de violencia política que azotó a Colombia.

Este proceso económico produjo cambios demográficos que modificaron radicalmente la dinámica de urbanización que traía la ciudad de Bogotá desde La Colonia; el centro de la ciudad se densificó, aparecen los "inquilinatos" como soluciones de vivienda para las familias migrantes que no encontraron un albergue independiente. Así, la población empieza a presionar las haciendas y ejidos ${ }^{2}$ ubicados en lo que era la periferia de la ciudad para allí establecer los primeros barrios denominados informales. ${ }^{3}$

De igual forma, el fenómeno de la inmigración del campo hacia las ciudades por razones de inseguridad se acrecienta en la segunda mitad del siglo XX en Colombia; se puede decir que los colonizadores de las periferias son emigrantes de primera o segunda generación que no encontraron respuesta a sus carencias de hábitat en el Estado ni fueron receptores del derecho a la seguridad por parte de los agentes estatales.

En los años sesenta el crecimiento poblacional había desbordado la capacidad de planeación del Estado y el retraso de vivienda calculado era de 22 años. Ante este contexto, el sector El Codito surge cuando la ciudad empieza a invadir las montañas de su borde oriental. Así, los primeros asentamientos se comenzaron a ubicar sobre la hoy conocida calle 174 por encima de la carrera séptima.

2 Los ejidos son tierras comunales cuya destinación estaba sujeta al goce y disfrute de la gente. Eran terrenos destinados al interés común lo que facilitaba el asentamiento de familias sin los recursos necesarios para subsistir en la ciudad.

3 Se denomina a estos barrios como informales dado a que no se observaron elementos técnicos ni de planeación en su construcción. 


\section{Elementos históricos de la conformación territorial de Usaquén}

La localidad de Usaquén, desde épocas coloniales, ha sido sujeta a ejercicios de planeación y definición de usos que, en ocasiones, riñen con la conformación social del espacio. Como ejemplo de este ejercicio de planeación externo, Zambrano et al. (2002) señala la fundación de la parroquia de Usaquén como forma de eliminar las tierras indígenas no comerciales y como inserción de un territorio estratégico: de movilidad y entrada a la capital durante la República y, en tiempos modernos, de contrabando, narcóticos e interacciones ciudad-región.

También se observa cómo el resguardo de indios de Usaquén fue trasladado a Soacha, lo que facilitó el uso económico de estas tierras ya que el pie y la falda de la montaña se convirtieron en tierras de ganado y agricultura. Ello condujo a que se posicionaran como proveedoras de alimentos de la capital del Virreinato.

De este modo, la lógica del español blanco se impuso sobre los territorios anteriormente indígenas; el control se realizó mediante el poblamiento sistemático a través de la instalación de familias completas, la adecuación de inmobiliarios y redes para incrementar la habitabilidad de la ciudad y el mantenimiento de las relaciones de dominación con la población indígena (ibídem).

Años posteriores a la expulsión de los conquistadores españoles, la concentración de la tierra a lo largo y ancho del territorio nacional se localizó en pocas manos; para comienzos del siglo XX, y a pesar del nuevo fenómeno de parcelación, la distribución efectiva de la tierra no logró su objetivo. Zambrano et al. (2002) argumenta que el propósito distribuidor no se cumplió debido a que, en su mayoría, quienes se hicieron arrendatarios de los nuevos lotes y terrenos eran medianos propietarios cuyo objetivo era consolidar un extenso territorio a partir de la adquisición de pequeñas parcelas.

Es claro que el territorio de Usaquén no escapó a esa dinámica nacional ni a otros procesos que envolvían el desarrollo de Bogotá. 
Usaquén ejemplificó el repartimiento de tierras indígenas que se estableció en la sabana de Bogotá, en la que predominaron los intereses de los grandes terratenientes y la extinción de la pequeña propiedad (ibídem). Entonces, desde finales del siglo XIX y la primera mitad del XX, Usaquén se erigió como un territorio estratégico para el desarrollo de la ciudad: primero, como principal proveedor de piedra y arena para su construcción; ${ }^{4} y$ segundo, como era el poblado más cercano al norte de Bogotá, se convirtió en la puerta de entrada a la capital (ibídem).

\section{Usaquén se anexa a Bogotá}

En el año de 1955, la ciudad de Bogotá se convierte en Distrito Especial. Este cambio se produjo con la anexión de los municipios vecinos de Bosa, Usme, Fontibón, Engativá, Suba y Usaquén. Desde ese momento, el municipio de Usaquén pasa a ser considerado una unidad territorial de la capital de Colombia.

Una de las razones por las cuales se produjo la anexión de estos municipios a Bogotá fue la búsqueda de independencia de la ciudad sobre la autoridad del departamento de Cundinamarca. No obstante, la presión propia del crecimiento urbano y la conexidad proveniente de diferentes proyectos de infraestructura también son causantes de esta anexión impuesta.

Zambrano et al. (2002) expresa que uno de los problemas con los que han lidiado las diferentes administraciones de la ciudad ha sido el crecimiento desmedido de la población bogotana a lo largo del siglo XX; cuestión que ha significado la disociación entre la planeación técnica y la definición de políticas desarrollistas estatales para la ciudad. En efecto, "Este crecimiento acelerado acarreó una urbanización descontrolada, donde los barrios marginales accedían a su normalización urbanística gracias a la mediación de algunos políticos inescrupulosos" (ibídem, p. 258).

4 Se dice inclusive que la piedra y arena con que se construyó el antiguo Palacio de Justicia y el Congreso de la República salieron de estas montañas. Recuperado de http://www.ciudadbogota. $\mathrm{com} /$ conte/historia/localidades/usaquen.htm 
Este suceso se complementa con la construcción de proyectos de infraestructura de cierta envergadura que facilitaban el acceso a diversos predios y la posibilidad de su negociación. Con la llegada de nuevos habitantes a los territorios deshabitados se aumentó la demanda de servicios públicos (ibídem).

Particularmente, la anexión de Usaquén, al ser un sitio de extracción de recursos naturales se podría relacionar con la búsqueda de recursos a menor costo que se utilizaran como insumos en la construcción de los nuevos asentamientos citadinos. La importancia de Usaquén como proveedor de recursos para la construcción ha dejado su huella sobre los cerros orientales de la ciudad. A ello se debe gran parte del debate sobre la definición de la reserva forestal sobre estos cerros.

En los años setenta, la política estatal de promoción de vivienda generó fuertes transformaciones en el espacio de la localidad. No sólo por la innumerable cantidad de proyectos de vivienda que se ejecutaron en la época, sino porque además el UPAC ${ }^{5}$ posibilitó la construcción de zonas comerciales, como el centro comercial Unicentro (ibídem, 2002).

Aunque estos proyectos hicieran parte de la planeación distrital contrastan con otros procesos de asentamiento y urbanización al interior de la localidad, como los que se observarán más adelante y que ayudaron a conformar el sector El Codito.

Antes de avanzar y adentrarnos en el caso de El Codito, se quiere reseñar la importancia que tiene para el sector el asentarse sobre los cerros orientales de la ciudad.

5 La Unidad de Poder Adquisitivo Constante (UPAC) fue un sistema de crédito hipotecario que se implantó en el gobierno de Misael Pastrana Borrero (1970-1974) que le permitía a los colombianos adquirir viviendas a largo plazo. 
62

\title{
La barrera natural de Bogotá: los cerros orientales
}

\author{
Juan David Guevara Salamanca \\ Con la colaboración de Natalia Molina Llano 6
}

Los cerros orientales de Bogotá son considerados de alta importancia para la ciudad y la región de Cundinamarca: por un lado, se constituyen como emblema que representa una identidad cultural de los bogotanos y se conciben como el principal referente paisajístico de la Capital, dada su "calidad escénica, dominancia visual y los valores intrínsecos (naturales) y los adquiridos (históricos y culturales)" (Mesa Ambiental de Cerros Orientales, 2008, p. 23); por otro lado, los cerros han sido, desde sus inicios, un escenario de gran importancia y valor ecológico, pues además de ser la más grande fuente de agua y oxígeno de la ciudad, recursos necesarios e imprescindibles para la supervivencia del ser humano, albergan miles de especies de fauna y flora, son el corredor ecológico que une al Parque Natural Nacional Chingaza con el Parque Natural Nacional Páramo de Sumapaz. Por lo anterior, se consideran "un eje ambiental de vital importancia que garantiza la calidad ambiental, la conectividad ecológica y la disponibilidad de servicios ambientales del Distrito, el cual forma parte de la Estructura Ecológica Principal de la Ciudad" (Personería de Bogotá, 2007, p. 10).

Así como el aspecto ecológico recobra gran importancia, los cerros también son residencia de distintos procesos urbanos en el que familias y comunidades han hecho de estos territorios el locus donde han desarrollado sus vidas, han tejido sus sueños y construyen prácticas familiares y comunitarias. Miles de personas han encontrado en los cerros orientales un lugar donde vivir, donde satisfacer sus necesidades básicas, donde ejercer sus derechos. Su historia, el trabajo realizado, la consolidación de los barrios, entre otras cosas, hacen que estas miles de familias sientan y conciban los cerros no solo como un espacio natural de importancia ecológica y paisajística, sino que identifiquen su sitio de residencia como su territorio.

6 Fonoaudióloga de la Universidad del Rosario. Especialista en Salud Pública de la Universidad del Rosario. Correo electrónico: namollan@gmail.com 
Dado a la permanente acción del hombre sobre este territorio, no solo por la ocupación territorial, sino además por la importancia recursiva, principalmente para los constructores de la ciudad, se inicia desde las diferentes instancias gubernamentales una avanzada normativa para preservar la riqueza ecológica y natural de los cerros y para evitar las acciones destructivas de la mano humana.

De esta manera, se han expedido normas que han oscilado entre las visiones de preservación, las cuales "restringen en mayor medida los usos de suelo sobre el área de la reserva y por lo mismo la presencia humana en la zona" (Bohórquez, 2008, p. 235), y las de conservación.

Lamentablemente, y aunque en la actualidad se lleva a cabo un proceso definitivo en el Consejo de Estado, ninguna definición normativa ha buscado conciliar las necesidades ecológicas y de preservación con las necesidades e intereses de los pobladores de la ciudad. Se espera que la resolución jurídica del Consejo de Estado defina, de una vez por todas, la situación de incertidumbre y abandono que reina las realidades de los cerros orientales.

\section{Desarrollo histórico de los cerros orientales}

Desde la Colonia, la explotación descontrolada, insostenible e intensiva marca la vida futura de los cerros orientales de Bogotá (Camargo, 2001). Esta explotación colonial va a tener sus raíces en los intereses y necesidades dominativas de los españoles por derrocar las deidades muiscas, cuya identidad está fuertemente relacionada con el territorio.

De hecho, esta porción territorial tenía un valor y significado religioso para la cultura muisca: algunas especies de animales y lugares sagrados, en particular las lagunas, cuyo hábitat son los cerros, servían como tótem dedicados a la adoración y a la realización de cultos y ceremonias.

Por esta razón, los españoles, en su afán de exterminar las creencias paganas y de "civilizar" a los "salvajes", ordenaron la tala de los bosques de nogales, encenillos, cedros gigantes y otras especies nativas para evitar que los muiscas adoraran estos árboles, y así aprovechar la buena madera para la construcción de templos y casas, y la elaboración de muebles y enseres para personajes ilustres de la época (Personería de Bogotá, 2007, p. 19). 
En los años treinta y cuarenta de la centuria pasada, la mayor parte de los cerros estaba por completo deforestada debido al uso de la madera para la subsistencia humana: la construcción de las casas, la calefacción de las viviendas, la cocción de los alimentos, entre otros, fueron los detonantes de esta destrucción.

A mediados de los años cincuenta se inicia un arduo proceso de reforestación con especies foráneas como los pinos de pátula, eucaliptos, cipreses y acacias, con el fin de volver a cubrir el cerro de vegetación. Sin embargo, estas plantaciones forestales exóticas no nativas producirían unas transformaciones no sólo en el paisaje de la ciudad sino en el ecosistema de los cerros.

De hecho, estas nuevas especies alteran la "dinámica hídrica de las microcuencas, proceso reflejado en la desaparición de cauces, disminución de la infiltración en las áreas de recarga, degradación de suelos y aceleración de procesos erosivos" (Díaz, s. f. p. 4). En el año 2006, según el Plan de Manejo Ambiental dado por la CAR, el 18\% del total de las hectáreas de la reserva forestal, sufre una amenaza en su estabilidad ecológica por el uso del suelo en dichas plantaciones forestales foráneas (Corporación Autónoma Regional de Cundinamarca, 2006).

En esa misma década, se vive en el país una gran migración de personas desplazadas por la violencia y por la carencia de trabajo rural que, dejando sus tierras y pertenencias, llegan a la capital en busca de empleo, una vivienda digna y una nueva posibilidad de rehacer sus vidas y sueños. Entonces, estas familias llegan a lugares de la ciudad en los que es posible acceder a una solución de vivienda a bajo costo, lo que lleva a que surjan asentamientos humanos en zonas no aptas para construcción con pocas condiciones de seguridad. Así, "se forma una población urbana marginal, excluida, estigmatizada y abandonada por el Estado en su conjunto" (Alcaldía Mayor de Bogotá, 2006, p. 7).

En los primeros años de la década del setenta, el Distrito lanza, en asocio con el Banco Interamericano de Desarrollo (BID), el Programa Integral para el Desarrollo Urbano de la Zona Oriental de Bogotá (Piduzob), cuya obra principal fue la construcción de la Avenida de los Cerros, hoy 
Avenida Circunvalar. El propósito de esta obra era integrar el norte con el centro de la ciudad, aprovechando las laderas de las montañas orientales.

\section{La explosión normativa}

Siguiendo la tradición santanderista, elemento identitario de la nación colombiana, el inmenso número de leyes, decretos, acuerdos, ordenanzas cuyo principal objetivo ha sido el de regular la vida social, económica, política y ecológica sobre los cerros, ha carecido de efectos y sentido al no tener en cuenta las poblaciones asentadas sobre estos territorios.

Así, existe una ubérrima normatividad que en no pocas ocasiones llama a la contradicción y el descontento al expresar puntos confusos sobre las posibilidades y prohibiciones del uso del suelo de la reserva, sin contar los desentendidos en cuanto a la definición misma de la reserva. Muchos lineamientos y principios se presentan como faltos de claridad y con vacíos jurídicos.

A continuación, se presenta la normatividad que se ha expedido para el manejo de los cerros orientales de Bogotá y la cual fue hallada en este proceso de entendimiento sobre la realidad jurídica de esta región tutelar de la ciudad.

Tabla 1. Normatividad para el manejo de los cerros orientales

\begin{tabular}{|l|l|}
\hline \multicolumn{1}{|c|}{ Norma } & \multicolumn{1}{c|}{ Descripción } \\
\hline $\begin{array}{l}\text { Acuerdo N. }{ }^{\circ} 30 \text { de } 1976 \\
\text { del Inderena }\end{array}$ & $\begin{array}{l}\text { Alindera y declara los cerros orientales como Área Forestal } \\
\text { Protectora Bosque Oriental de Bogotá y delega su administra- } \\
\text { ción en la CAR. }\end{array}$ \\
\hline $\begin{array}{l}\text { Resolución N. }{ }^{\circ} 76 \text { de } \\
1977 \text { del Ministerio de } \\
\text { Agricultura }\end{array}$ & $\begin{array}{l}\text { Adopta y eleva a categoría de decreto nacional el Acuerdo 30 } \\
\text { de 1976 del Inderena. }\end{array}$ \\
\hline $\begin{array}{l}\text { Acuerdo 1 de 1986 del } \\
\text { Concejo de Bogotá }\end{array}$ & $\begin{array}{l}\text { Se ordena la legalización de un conjunto de desarrollos exis- } \\
\text { tentes a la fecha de su expedición. Visibiliza la legalización } \\
\text { de 27 asentamientos localizados en el borde oriental de la } \\
\text { ciudad. }\end{array}$ \\
\hline
\end{tabular}




\begin{tabular}{|c|c|}
\hline Norma & Descripción \\
\hline $\begin{array}{l}\text { Acuerdo } 59 \text { de } 1987 \text { de } \\
\text { la CAR (derogado por el } \\
\text { Acuerdo } 38 \text { de 1990) }\end{array}$ & $\begin{array}{l}\text { Por el cual se expide la reglamentación de los cerros orienta- } \\
\text { les de Bogotá. Establecía unas normas de manejo ambiental y } \\
\text { paisajístico para la conservación de la reserva, atendiendo a } \\
\text { las distintas situaciones de hecho y potenciales, por medio de } \\
\text { una zonificación. Es derogado pues contiene normas de uso } \\
\text { e índices de ocupación para las diferentes zonas por lo cual } \\
\text { adquiere perfil de norma urbanística. }\end{array}$ \\
\hline Acuerdo 6 de 1990 & $\begin{array}{l}\text { Por medio del cual se adopta el estatuto para el ordenamiento } \\
\text { físico del Distrito Especial de Bogotá y se dictan otras dispo- } \\
\text { siciones. Responde a la obligación impuesta por la Ley } 9 \text { de } \\
1989 .\end{array}$ \\
\hline Acuerdo 38 de 1990 & $\begin{array}{l}\text { Se ratifica la Resolución } 76 \text { de } 1977 \text { como norma de cerros } \\
\text { orientales, interpretada la reserva en sentido del uso forestal } \\
\text { exclusivo. }\end{array}$ \\
\hline $\begin{array}{l}\text { Resolución } 2413 \text { de } 1993 \\
\text { de la CAR }\end{array}$ & $\begin{array}{l}\text { Por la cual se sustrae un área de la Reserva Forestal Protecto- } \\
\text { ra Bosque Oriental de Bogotá. } \\
\text { "Aprovechando el antecedente creado por la Resolución } \\
2337 \text { de } 1985 \text { (cuando la CAR sustrae el sector de San Luis- } \\
\text { La Sureña), la Sociedad Reforestadora Puente Chicó solicita } \\
\text { que los terrenos de su propiedad (aledaños a La Sureña) sean } \\
\text { sustraídos de la Reserva Forestal Protectora, alegando que } \\
\text { continuamente son invadidos ilegalmente por las personas } \\
\text { procedentes de los barrios legalizados vecinos, lo que permi- } \\
\text { te la extensión de la urbanización sobre la quebrada Chicó" } \\
\text { (Camargo, s. f., p. 11). }\end{array}$ \\
\hline $\begin{array}{l}\text { Acuerdo } 31 \text { de } 1996 \text { del } \\
\text { Distrito }\end{array}$ & $\begin{array}{l}\text { Por el cual se adopta el Plan de Ordenamiento Físico del Borde } \\
\text { Norte y Oriental de la Ciudad de Santa Fe de Bogotá D. C., } \\
\text { se establecen las normas urbanísticas y las medidas para la } \\
\text { preservación, protección y adecuado uso de las áreas que } \\
\text { conforman dichos sistemas y se dictan otras disposiciones. }\end{array}$ \\
\hline Decreto 619 de 2000 & $\begin{array}{l}\text { Por el cual se adopta el Plan de Ordenamiento Territorial } \\
\text { para Santa Fe de Bogotá, D. C. Se incluye dentro del Sistema } \\
\text { de Áreas Protegidas del Distrito Capital, la Reserva Forestal } \\
\text { Protectora Bosque Oriental de Bogotá, como un área protegi- } \\
\text { da del orden nacional. }\end{array}$ \\
\hline $\begin{array}{l}\text { Plan de Ordenamiento } \\
\text { y Manejo de los Cerros } \\
\text { Orientales de Bogotá } \\
\text { (Pomco) del año } 2004\end{array}$ & $\begin{array}{l}\text { Elaboración de un diagnóstico de los cerros orientales, análi- } \\
\text { sis prospectivo y zonificación de manejo. }\end{array}$ \\
\hline
\end{tabular}




\begin{tabular}{|l|l|}
\hline \multicolumn{1}{|c|}{ Norma } & \multicolumn{1}{c|}{ Descripción } \\
\hline $\begin{array}{l}\text { Resolución N. }{ }^{\circ} 463 \text { de } \\
\begin{array}{l}\text { Ambiente, Vivienda y } \\
\text { Desarrollo Territorial }\end{array}\end{array}$ & $\begin{array}{l}\text { Redelimita la Reserva Forestal Protectora Bosque Oriental de } \\
\text { Bogotá, se adopta su zonificación y reglamentación de usos y } \\
\text { se establecen las determinantes para el ordenamiento y ma- } \\
\text { nejo de los cerros orientales de Bogotá. }\end{array}$ \\
\hline $\begin{array}{l}\text { Resolución DAMA 1043 } \\
\text { del 28 de abril del 2005 }\end{array}$ & $\begin{array}{l}\text { Por medio de la cual se establece una medida preventiva y se } \\
\text { toman otras determinaciones en relación con la reglamen- } \\
\text { tación adoptada por el Ministerio de Ambiente, Vivienda y } \\
\text { Desarrollo Territorial, para el Área de Reserva Forestal Pro- } \\
\text { tectora Bosque Oriental de Bogotá, D. C. }\end{array}$ \\
\hline $\begin{array}{l}\text { Resolución 463 de 2005 } \\
\text { del Ministerio de Am- } \\
\text { biente, Vivienda y Desa- } \\
\text { rrollo Territorial }\end{array}$ & $\begin{array}{l}\text { Por medio de la cual se redelimita la Reserva Forestal Protec- } \\
\text { tora Bosque, se adopta su zonificación y reglamentación de } \\
\text { usos y se establecen las determinantes para el ordenamiento y } \\
\text { manejo de los cerros orientales de Bogotá. }\end{array}$ \\
\hline $\begin{array}{l}\text { Decreto (distrital) } \\
\text { N. }{ }^{\circ} 122 \text { de 2006 }\end{array}$ & $\begin{array}{l}\text { Por el cual se adoptan medidas de defensa y protección de la } \\
\text { Reserva Forestal Protectora Bosque Oriental de Bogotá. }\end{array}$ \\
\hline $\begin{array}{l}\text { Resolución N. }{ }^{\circ} 1141 \text { de } \\
\text { 2006 de la Corporación } \\
\text { Autónoma Regional de } \\
\text { Cundinamarca }\end{array}$ & $\begin{array}{l}\text { Adopta el Plan de Manejo Ambiental de la Zona de Reserva } \\
\text { Forestal Protectora Bosque Oriental de Bogotá. }\end{array}$ \\
\hline
\end{tabular}

\section{Urbanización de los cerros}

El proceso de urbanización de los cerros orientales inició mucho antes de que estos fueran declarados reserva natural en 1976. No solo ha sido el asentamiento de gentes avenidas a marginalizadas y excluidas, como las poblaciones de El Codito, sino también les han sido sitio de residencia de personas lo suficientemente incluidas y poderosas para violar la norma (Camargo, 2001).

La mayoría de predios que no fueron adquiridos por la Empresa de Acueducto y Alcantarillado de Bogotá, con el fin de preservarlos, se fueron transformando o ya eran canteras, tugurios, proyectos institucionales o condominios de lujo. Pese a lo reglamentado en todos los acuerdos, resoluciones y decretos concernientes a la preservación y conservación de los recursos naturales no renovables y el paisaje como patrimonio común de la humanidad, las autoridades ambientales, motivadas por razones urba- 
nísticas, autorizaron (mediante resoluciones y actos legislativos) sustraer áreas de la "zona de Reserva Forestal de los Bosques Orientales", antes que ejercer verdaderas y efectivas acciones para su preservación.

Así las cosas, específicamente en estratos socioeconómicos 1 y 2 el proceso de desarrollo urbano se inició, de una parte, con el asentamiento de familias que al dedicarse a la extracción de materiales para la construcción decidieron establecerse en los cerros orientales cerca a su lugar de trabajo; y, de otra, la llegada de personas que por el bajo costo del predio y las oportunidades de adquisición se instalan en ellos. Desde entonces, ha existido un proceso de expansión urbana subnormal que roba permanentemente territorio a la reserva forestal y deteriora los recursos naturales y el ecosistema.

La conexión ilegal a los servicios públicos era parte de la cotidianeidad de los habitantes de los cerros. El loteo de haciendas existentes desde épocas coloniales fue una práctica común que, sin legislación y control de las autoridades, les permitió a muchos habitantes tener una fracción de tierra donde vivir.

Mientras tanto, las autoridades de la ciudad definían políticas para ponerle freno al crecimiento informal y no planificado de Bogotá. Así, en el año de 1968 se expide la Ley 66 que tenía como objetivo regular el uso de la tierra en las ciudades y penalizar la venta ilegal de lotes y las urbanizaciones "piratas".

Posteriormente, se crea el Comité Permanente de Control y Administración de Urbanizaciones teniendo como labor principal vigilar los procesos de construcción llevados a cabo en la ciudad. Su primera tarea fue la de realizar un censo sobre los denominados "barrios piratas"; en marzo de 1975, el estudio arrojó que de 698 barrios que había en Bogotá solo 400 eran legales (El Tiempo, 1975).

Algunos de los barrios actuales, tanto como los que se encuentran legalizados como aquellos que aún no han sido reconocidos, se iniciaron como procesos de invasión o como producto del pago del trabajo realizado en las canteras por parte de los dueños de las haciendas y los chircales.

Es preciso anotar que desde que los cerros orientales fueron declarados reserva forestal, se han percibido múltiples inconsistencias por parte de 
las autoridades y entidades del Estado en temas relacionados con la adjudicación de licencias, la legalización de barrios y la prestación de servicios públicos domiciliarios.

En lo relacionado con estos últimos, en un comienzo la mayoría de los barrios no contaban con servicios de electricidad, agua y alcantarillado por lo cual les era necesario "contrabandear" o buscar la forma de autodotarse dichos recursos. Con el paso del tiempo, la realidad de la ciudad fue exigiendo a las empresas y al distrito que esos servicios fueran provistos y, por esto, en 1998 la Empresa de Acueducto y Alcantarillado de Bogotá desarrolla el "Programa de Desmarginalización, el cual es avalado por la Nación y se financia con recursos del Banco Mundial y del Banco Popular. A través de dicho Programa se suministra agua a más de 650 barrios promovidos por urbanizadores piratas, varios de ellos localizados dentro de la reserva forestal” (Alcaldía Mayor de Bogotá, 1998, p. 12).

Algunos sectores y barrios lograron conseguir la prestación de los servicios aun estando inmersos en el área protegida. Sin embargo, muchos otros todavía no logran el acceso a estos.

Actualmente, el sector El Codito tiene una cobertura casi total de los servicios públicos. Según Mendoza y Guevara (2012), en el sector hay una cobertura del 100\% de energía eléctrica, 94\% de acueducto, 91\% de alcantarillado y $89 \%$ de gas natural. Los barrios Serrezuela, Lomitas, La Capilla, Mirador del Norte y un sector de Balcones de Vista Hermosa, desde hace aproximadamente 30 años, han tenido que enfrentar un problema de cobertura en los servicios de acueducto y alcantarillado pues al ser barrios no legalizados y que se encuentran ubicados en medio de la reserva forestal, no reciben respuesta positiva por parte de las empresas prestadoras de estos servicios por la imposibilidad de intervenir en zonas no permitidas.

Así mismo, en relación con el servicio de gas natural, según comentan algunos habitantes de los barrios en mención, tan solo desde hace menos de un año, se logró, por intermediación de algunos líderes comunitarios, que la empresa Gas Natural realizara la instalación de redes. Esto da cuenta de las dificultades presentes para los habitantes de estos barrios.

Por otro lado, en lo relacionado con los estratos socioeconómicos 5 y 6, al amparo de supuestas plantaciones forestales privadas, en zonas que 
fueron sustraídas de la reserva forestal por resoluciones de la CAR y que actualmente se consideran nulas, se inició la construcción de urbanizaciones, edificios, instituciones educativas, que asumen un modelo sostenible que permita mantener un equilibrio entre la naturaleza y el hombre. Pese a eso, la urbanización y construcción ha implicado deforestación, la ruptura del curso normal de corrientes hídricas y por ende del ecosistema (Camargo, s. f., p. 9).

Se podría resumir que los procesos de asentamiento en los cerros se caracterizan, entre otros aspectos, por: el tráfico de influencias para la otorgación de licencias de construcción, la prevalencia de algunos intereses económicos empresariales — como el caso de las canteras-, la abundante y confusa legislación existente sobre el tema, la carencia de moralidad administrativa de algunos servidores públicos, el soslayo de la ley por parte de algunos habitantes de los cerros, entre otros aspectos (Alcaldía, 2006).

\section{El hombre y la naturaleza. ¿Determinantes en la política pública sobre los cerros orientales de Bogotá?}

La Resolución 76 de 1977 del Ministerio de Agricultura, en la cual se "alinda y declara la Reserva Forestal Protectora del Bosque Oriental de Bogotá”, fue la primera iniciativa en proteger a los cerros orientales y la preservación de sus recursos naturales no renovables. Sin embargo, al tener en cuenta las restricciones que en términos de uso, aprovechamiento y transformación de las áreas que estaban allí implícitas, y que se consideraba ilegal la reglamentación de los procesos urbanos como el ordenamiento del comercio, los corredores viales y la expansión suburbana, procesos que se venían adelantando desde hacía más de 20 años, se considera esta resolución como el punto de partida para la problemática y el debate actual de esta zona de la ciudad (Camargo, s. f., p. 10).

La forma como las entidades estatales han interactuado con las poblaciones asentadas en estos territorios se ha limitado a la promulgación de normas, acuerdos, resoluciones y leyes. Ello ha consolidado procesos unilaterales en los cuales se desconocen por completo las percepciones, intereses y necesidades de los pobladores dando relevancia a los valores e 
intereses ambientales y paisajísticos. En pocos momentos se han utilizado herramientas de planeación y participación ciudadana para formular planes y normas, lo que limita la posibilidad de conocer la definición social y espacial de la zona de reserva forestal y de la supuesta zona de adecuación, la construcción del sentido de pertenencia y el fomento al cuidado y sostenibilidad de la reserva. Este proceso ha generado un "efecto social y ambiental negativo, al simbolizar los elementos naturales como antivalores del desarrollo" (ibídem, p. 11).

Pese a la existencia de la Mesa Ambiental de los Cerros Orientales con sus propuestas y documentos que han sido presentados al gobierno distrital, aún no se cuenta con elementos de planeación que logren la confluencia de los intereses urbanos, locales, distritales, económicos, ambientales y sociales.

Al considerar la política pública como "un programa de acción gubernamental que tendría por lo menos cinco fases -identificación de un problema, formulación de soluciones, toma de decisión, implementación y evaluación-" (Bohórquez, 2008, p. 231), se puede concluir que aún no se cuenta con una política pública integral para los cerros orientales.

A pesar de que existe un sinnúmero de normas, la realidad jurídica colombiana y la fáctica realidad de los cerros orientales nos lleva a concluir que no es necesaria la existencia de una política pública de los cerros si esta no se identifica, formula, ejecuta y evalúa bajo preceptos participativos, con el ánimo de lograr el efectivo cumplimiento de la legislación de los cerros.

En este orden de ideas, el hombre y la naturaleza son concebidos como elementos que en vez de compenetrarse y complementarse, actúan como enemigos y obstáculos para el desarrollo de cada cual, dejando de ser vistos como "elemento y conjunto, sino como dos antagonistas, dos existencias recíprocamente excluyentes" (Camargo, 2006, p. 2). La realidad de los cerros parece contener estos elementos contradictorios pero complementarios. Falta ver cómo se resuelve el embrollo jurídico y si se desencadenan propuestas sostenibles para las poblaciones y la riqueza ecológica de los cerros orientales de Bogotá.

En el marco de las propuestas alternativas se quiere hacer especial mención a la propuesta del Pacto de Bordes, impulsada y expuesta por actores como Hernando Gómez (ex alcalde de Chapinero) y la Asociación de 
Cerros Orientales de Bogotá. Esta propuesta parece encajar en la fórmula hombre-naturaleza al traspasar la responsabilidad de preservación y conservación del recurso natural a los pobladores de los barrios ubicados sobre los cerros orientales. Aquí, el recurso natural queda en manos de los habitantes de las montañas capitalinas quienes deben conjugar la convivencia con el respeto por la naturaleza.

\section{De lo local a lo barrial. Procesos históricos de conformación territorial del sector El Codito}

En el siguiente apartado se propone hacer un recorrido por la consolidación espacial de El Codito. La forma que se hace la apropiación del territorio y el papel de los actores que facilitaron este proceso son los puntos de mayor importancia en este acápite.

También se hace especial énfasis en las luchas sociales del sector, cuyo elemento compartido se puede observar en otros territorios. El acceso a los servicios públicos domiciliarios y el reconocimiento de las autoridades distritales fueron los hechos más representativos de los primeros días de El Codito.

\section{El modelo hacendista como crisol de los años venideros}

El poblamiento de El Codito obedece al proceso de urbanización histórico de la ciudad de Bogotá y, en particular, de la actual localidad de Usaquén. En este proceso, la conformación del territorio recibe influencias de la organización espacial de la colonia española, del lento poblamiento de los primeros años de la República y de la explosión urbana de la década de los años cuarenta del siglo pasado.

En el momento de la anexión a Bogotá, el hoy llamado sector El Codito tenía solo tres casonas: la finca Horizontes, la finca La Estrellita y una casona que se proyectó como la urbanización Buenavista que nunca llegó a concluirse. En especial, estas fincas obedecieron al sistema hacendista que reinó en Colombia como modelo definitorio y organizador del espacio social, 
económico y cultural, igualmente, como expresión histórica del territorio y como ejercicio productivo que primó hasta el siglo XX.

Este modo de organización del territorio se basaba en la tenencia de grandes extensiones o latifundios de tierra en manos de pocas personas o familias, como lo expone Zambrano et al. (2002).

Se aclara que, aunque las tierras de El Codito no comparten la extensión que otros terrenos tenían en Colombia, la lógica productiva del espacio obedecía a los mismos patrones de las grandes haciendas.

Según Guillén (1979), el modo de producción de la hacienda tuvo su sustento en la cada vez más deficiente producción de explotación agraria de los resguardos indígenas; la dación de recompensas militares con la concesión de tierras públicas, tierras baldías o confiscadas en manos del Estado; la destrucción de los centros de producción manufacturera artesanal del nororiente del país; y de la apertura aduanera al comercio internacional.

Con la Hacienda, la estructura económica del país se perfiló como exclusiva productora de alimentos y materias primas; pero no sólo se convirtió en estructurador económico sino además moldeó las relaciones políticas y sociales (Guillén, 1979).

El poder expedido desde la Hacienda se basaba en el libre cambio, en la práctica del monocultivo exportador, en la centralización del poder y las alianzas de clase, y en el mantenimiento de la subordinación social y hereditaria (Guillén, 1979). Principalmente, este modelo se expandió por el centro del país, a excepción del occidente antioqueño y del viejo Caldas. Este modo de producción económico, espacial, político y social dominó la escena colombiana hasta la segunda mitad del siglo XX.

Para Usaquén, la forma de Hacienda se asume en su singular forma ganadera, lo cual sirvió para reforzar la idea de diferenciación social del espacio. ${ }^{7}$ Diferencia que hoy día se percibe en la estratificación de la localidad cuya población mayoritaria pertenece a los estratos 5 y 6 .

Un hecho para resaltar es que las haciendas dedicadas a la ganadería extensiva no necesitan gran cantidad de mano de obra, diferente a las ha-

7 Se destaca el hecho de que a lo largo del siglo XIX y comienzos del XX, las tierras de Usaquén servían como sitio de descanso y recreo para las familias acomodadas de la sociedad bogotana. 
ciendas dedicadas a la agricultura. Esto fue determinante en el proceso de poblamiento en el siglo XIX dado que Usaquén no logró concentrar la misma cantidad de población que en los pueblos y lugares del sur y sur-oriente de Bogotá (Zambrano et al., 2002).

Además, las características morfológicas y naturales de Usaquén marcaban un distanciamiento con las tierras áridas del sur y noroccidentales de la ciudad, por lo cual las tierras verdes del norte se convirtieron en los nuevos sitios de asentamiento de las élites capitalistas, que provenían, principalmente, desde Chapinero ${ }^{8}$ (ibídem, 2002).

Esta movilidad de las élites se produce como parte de un ejercicio de distinción y estratificación ya que en la Bogotá de principios del siglo XX, las diferentes clases y estratos convivían en los mismos territorios; adicional a ello, se observa la incapacidad del gobierno de la ciudad de vencer las condiciones higiénicas contrarias a la salud, la calidad del suministro de agua, la inexistencia del alcantarillado cubierto, la ausencia de regulación y control sobre la disposición de los desechos. Todos estos factores contribuyeron "para que las élites buscaran un entorno que correspondieran a su capacidad económica" (ibídem, p. 202).

Además, estos terrenos se habían convertido en lugares privilegiados para veranear, lo que reforzó el desplazamiento de las élites a estos sitios del norte (ibídem).

El proyecto de construir el Ferrocarril del Norte, cuyo fin principal era conectar a Bogotá con Venezuela, permitió la consolidación de una ruta regional que llegaba hasta Chiquinquirá, pasando por Usaquén y Zipaquirá (ibídem, p. 231). Lo que fortaleció la importancia de las tierras de Usaquén para la consolidación de la ciudad.

En el caso específico de El Codito, la Hacienda significó el inicio del proceso de poblamiento del territorio, en forma de la explotación de canteras y, a la par, de la toma de tierras. La siguiente sección se enfocará en estos dos procesos distintos pero consolidantes de la realidad del sector.

8 Chapinero, a través de los años, ha sido el barrio receptor de las élites políticas y económicas de la ciudad. Sin embargo, desde los años setenta su transformación ha llevado a que sea reconocido principalmente como un barrio de residencia estudiantil y de población LGBTI. 


\section{Las canteras y los primeros asentamientos}

Hoy día, el sector El Codito está compuesto por los barrios: Horizontes, Mirador del Norte, Lomitas, Buenavista I y II, Llanurita I y II, El Codito, Altos de Serrezuela, Vecinos de la Capilla, Mirador del Norte parte alta, Balcones de Vistahermosa, Nuevo Horizonte, Las Mercedes, Chaparral, Estrellita del Norte y La Franja; esta difuminación territorial puede tener su causa en el proceso histórico de conformación territorial y espacial que se ha desarrollado en El Codito.

Es por ello que los próximos párrafos buscarán dilucidar los elementos, realidades y sucesos que han marcado, a través de los años, a El Codito, desde sus inicios hasta lo que en la actualidad se reconoce.

Históricamente se evidencia en la consolidación de la ciudad es, por un lado, su expansión territorial sin afectación de los humedales del norte y occidente y, por otro lado, la ocupación de las zonas altas de ladera a lo largo de las montañas limítrofes del oriente de Bogotá, como sitio para extraer materias primas necesarias para su construcción (ibídem, 2002).

Entonces, reviste especial importancia lo que anteriormente se había mencionado sobre la instalación y funcionamiento de sitios de explotación minera sobre los cerros orientales de Bogotá, que para nuestro caso son las ubicadas al norte de la ciudad.

En efecto, Zambrano (2002) identifica la existencia, desde el siglo XVII, de una mita urbana ${ }^{9}$ ubicada en el resguardo de Usaquén. Este hallazgo indica que desde tiempos coloniales los cerros tutelares de la ciudad de Bogotá eran reserva permanente de recursos naturales y minerales.

De acuerdo con la reconstrucción espacial del resguardo, se evidencia que las canteras coloniales son las mismas que se explotaron en el siglo XX, teniendo en cuenta que el resguardo comprendía los límites de la calle 100 al sur de la localidad y la calle 170 al extremo norte (ibídem, 2002). Para

9 La mita urbana de Santafé fue una forma laboral que se impuso en 1580. Consistía en que las poblaciones cercanas a Santafé estaban obligadas a enviar la población aborigen para que trabajara en las obras públicas y en otro tipo de trabajo pagos. Además, existieron otras mitas como la de minas y la leñera, en las cuales participó la población aborigen de Usaquén. (Zambrano et al., 2002, p. 137) 
el sector El Codito estos sitios denominados coloquialmente como "canteras" fueron los escenarios iniciales en los que se empezó el asentamiento poblacional sobre el territorio.

La principal razón de este hecho fue la llegada de familias provenientes principalmente de Tolima, Boyacá y Cundinamarca, quienes, desplazadas por la situación de violencia y las pocas oportunidades de generación de ingresos en las áreas rurales, buscaban mejorar su situación de empleo y seguridad.

A pesar de que el sector El Codito se ubica desde la calle 174, lo que nos lleva a concluir, de acuerdo con los hallazgos de Zambrano, la inexistencia de canteras coloniales, sí se conoce de barrios que fueron, en un momento de la historia del territorio, sitios de extracción de recursos naturales y minerales. En la zona, el ejemplo más representativo es el barrio que lleva su mismo nombre, El Codito.

Este barrio está ubicado en el extremo sur del sector (calle 174); los primeros habitantes llegaron al territorio en busca de una fuente de ingresos estable que les permitiera cumplir el sueño citadino. Esta fuente de ingresos fue la explotación de canteras, que no solo significó un espacio para ejercer la actividad laboral, sino además, un sitio de asentamiento, de generación de arraigo y comunidad (Gualteros \& Londoño, 2006).

Un elemento destacable en el proceso reciente de urbanización es que, por su posición geográfica, el sector El Codito sirvió para forjar lo que Zambrano (2002) denomina la ciudad tentacular: tipo de ciudad que se expande y densifica en los bordes de los caminos, avenidas y calles principales. ${ }^{10}$

El ensanche de la ciudad se fue dando de modo tal que no obedeció a un proceso planeado de ordenamiento territorial ejecutado por inversiones privadas o por la intervención directa del Estado, sino al asentamiento progresivo de familias en antiguas parcelas y haciendas ubicadas en el norte, sur y occidente de la ciudad (ibídem, 2002). La forma de urbanización

10 Causa especial atención que la ciudad reticular en su dependencia a las vías de acceso y comunicación de la ciudad pudo aumentar el interés de explotar los recursos mineros de las montañas tutelares de Bogotá, cuestión que se señala para investigaciones posteriores ya que desbordan el objetivo del presente trabajo. 
consistía en la adquisición y cesión de predios del dueño de los terrenos circundantes a la cantera, para que allí se asentaran los trabajadores de las canteras y sus familias.

Precisamente, este es el caso del barrio El Codito ya que una parte del barrio pertenecía a la familia Gaviria Valenzuela quienes, al trascurrir los días y la llegada de nuevos pobladores, decidieron vender esos terrenos para urbanizarlos (El Tiempo, 2011).

En la mayoría de los casos, las familias trabajaban para los dueños de las canteras, quienes les proveían, en algunos casos, la prestación de algunos servicios públicos. La llegada de una mayor cantidad de familias a lo que anteriormente eran terrenos aptos para la agricultura y ganadería condujo a la transformación de ese territorio a sitios de asentamiento humanos; razón por la cual "el sector pasó, poco a poco, de ser una zona rural a una zona urbana” (El Tiempo, 2011), por lo menos en su concepción territorial.

\section{La venta de lotes y la toma de tierras}

La inserción informal del sector El Codito a la realidad de la urbe capitalina y las dinámicas que ella produce se evidencian en esta etapa definitiva de la consolidación territorial y espacial del sector de las ventas de lotes y las ocupaciones informales.

Este momento de urbanización y conformación del sector se genera a partir de la acelerada oferta de tierras relativamente baratas, en el norte de la ciudad.

Esta oferta respondía al incremento acelerado de la población bogotana ${ }^{11}$ que, dado a la inflexibilidad de la oferta en vivienda por parte de los constructores de la capital, se asentaba de forma descontrolada en los barrios marginales, subnormales o informales, con lo que accedían a un proceso de normalización y legalización producto de la mediación de políticos inescrupulosos y clientelistas (Zambrano et al., 2002).

11 El incremento poblacional fue producto de diversos factores: el aumento de las tasas de natalidad, el decrecimiento de la tasa de mortalidad, y los desplazamientos generados por la violencia rural y las pocas oportunidades de subsistencia. 
De esto último se desprenden las diferencias en los procesos de urbanización en el norte de la ciudad, cuyo principal componente fue la subdivisión de haciendas pero por empresarios ilegales y legales de tierras; esto caracteriza al norte de Bogotá, en la medida en que fueron los propietarios de las haciendas quienes definieron la oferta de tierra para la construcción de los nuevos asentamientos (ibídem, 2002).

En efecto, este fenómeno obedeció a la subdivisión o parcelación de las haciendas, que para el caso de Usaquén, la mayoría fueron producidas por los propietarios de las mismas (ibídem, 2002).

Precisamente, Zambrano (2002) expone como característica en el proceso de construcción de los nuevos asentamientos, de los cuales los barrios de El Codito no son la excepción, la carencia en el seguimiento de normas urbanísticas, cuya evidencia fáctica se observa en la inexistencia de espacios públicos —en especial: parques, el trazado de calles y la instalación de redes de servicio público-.

Aquellas personas que tenían las posibilidades económicas de comprar una subdivisión de la hacienda — las haciendas eran divididas en lotes de seis metros de frente por doce metros de fondo cada uno--, dado a que la oferta en construcción era tan precaria, debían autoconstruir sus viviendas, de este modo se forjaron lo que hoy se conocen como barrios informales. ${ }^{12}$ De hecho, "los inmigrantes, que habrían llegado a vivir en pequeñas piezas hasta haber acumulado ahorros suficientes para acceder a una casa propia, compraban estos lotes a plazos y en ellos construían poco a poco sus casas" (ibídem, pp. 259-260).

Ahora bien, el proceso de urbanización también estuvo sujeto a los pleitos que llegaron a tener estos inmuebles parcelados dado que, y específicamente en El Codito, la posibilidad de los asentamientos se dio por la conflictiva situación jurídica de los terrenos. En palabras de Ángel y

\footnotetext{
12 Alrededor de este término se ha discutido con gran amplitud sobre la naturaleza y forma de designar a los barrios que han surgido a partir de procesos de autoconstrucción. Ejemplos de designación: barrios de invasión, barrios de recuperación de tierras, barrios informales, barrios ilegales, cinturones de miseria, barrios de pobres, etcétera. A nuestro entender algunos de estos términos obedecen a denominaciones ideológicas o peyorativas o legalistas, por lo cual el autor prescindirá la utilización de los mismos.
} 
Leguizamón (1999, p. 83) "esos terrenos se encontraban en pleito, pues los propietarios dejaron cuidando el terreno a unas familias hacía más de veinte años, a quienes no se les pagó sueldo ni prestaciones. Por ese motivo tomaron la determinación de ceder lo que ellos consideraban su posesión a familias que no tuvieran techo con la asesoría de Provivienda para que defendiera esos derechos".

A medida que el sector se convertía en receptor de familias y nuevos pobladores, las demandas de los nuevos y viejos habitantes se incrementaban. Ello condujo a que los habitantes del territorio se vieran en la obligación de generar alianzas y procesos de colectividad unos con otros: "Poco a poco empezaron a llegar más personas a habitar El Codito y se vio la necesidad de organizarse" (Gualteros \& Londoño, 2006, p. 19).

Aunque la anterior cita hace referencia al barrio El Codito, existe un elemento compartido por los barrios del sector: el llamado a la unidad por la reivindicación del derecho a la vivienda. Ya sea por el acceso a los servicios públicos domiciliarios o por el derecho a la propiedad sobre la vivienda. Zambrano expone esta idea de la siguiente manera:

De pronto queda atrás, apenas como parte de un pasado — para algunos desconocido-, el sentimiento de solidaridad que llevaba a la organización de una comunidad en torno a la lucha de unos derechos que, debido a sus necesidades, estado de marginalidad, o el abuso de urbanizadores le fueron negados (el agua, la electricidad, el teléfono, la recolección de basuras...) (2002, p. 281).

En efecto, la participación de los habitantes del sector coadyuvó a la conformación de los barrios "porque tal vez si mucha gente no se hubiera unido, este barrio no sería el que es ahora. Eran personas que luchaban por sacar este barrio adelante a pesar de los recursos y servicios que tenían" (Alba, A. et al., 2007, p. 17).

La defensa de estos nuevos asentamientos fueron apoyados por dos actores claves, ya sea para el momento de confrontación y lucha por el derecho a la vivienda o para la legalización y escrituración de las viviendas y la iniciación de nuevos procesos de trabajo colectivo en el sector. 
De este modo, el promotor de la toma de tierras, quien en años siguientes asumiría el proceso de escrituración y legalización de las tierras y subsecuentemente de las viviendas (recuperadas o tomadas) en El Codito, es la Central Nacional Provivienda (Cenaprov).

Cenaprov, perteneciente al Partido Comunista Colombiano (PCC), ${ }^{13}$ ha acompañado desde los años sesenta del siglo pasado los procesos de recuperación de tierras a lo largo y ancho del territorio colombiano. Así, el acompañamiento y la dirección en estos procesos se evidencian en departamentos como Cundinamarca, Tolima, Valle, Santander, Meta, Huila, Cundinamarca, entre otros.

En sus inicios, Provivienda se dedicó a organizar a los diferentes inquilinos de la ciudad de Cali, para realizar acciones combativas en procura de la adjudicación de lotes cuyo uso fuera de vivienda. Estas acciones se ejercían a partir de movilizaciones masivas e ilegales. Desde los años cuarenta, concomitante al nacimiento de los comités de Provivienda, se fijaron los principales objetivos de la asociación: la toma de tierras y solucionar el problema de vivienda (Salas, P. A. 1998).

En este primer momento, el ideario que guiaba el accionar de Provivienda, que para el año 1944 se constituía como Federación de Comités, era el de unificar "las acciones de los inquilinos para hacerle frente a la reacción del gobierno, la oligarquía y los terratenientes urbanos" (ibídem, 20).

Para el año 1959 se fundó Provivienda seccional Bogotá. El objetivo principal en Bogotá era "organizar a los inquilinos, defenderlos en todos los aspectos y conseguir vivienda por cualquier medio" (ibídem, 21). En esos años, se buscó obtener la personería jurídica, lo que se logró con el cambio de nombre de la organización, que pasó a ser llamada Cenaprov, tal como se conoce actualmente.

A pesar de que la organización promoviera la toma de las tierras, se mantenía un criterio legalista de respeto por el derecho a la propiedad

13 Hay algunas personas que ubican a Cenaprov como parte de la desaparecida Unión Patriótica (UP). La UP era un partido político de izquierda y centro izquierda cuyo origen se sitúa en la década de los ochenta como resultado del proceso de paz entre el gobierno del ex presidente Betancur y distintos grupos de izquierda democrática y en armas; el Partido Comunista Colombiano hizo parte de esta iniciativa política que sufrió su exterminio en años posteriores. 
privada (ibídem, 23). Fue por ello que la mirada se tenía sobre los suelos ociosos, improductivos o terrenos ejidos.

Un primer trabajo que se tuvo que realizar en Bogotá fue el de identificar ese tipo de terrenos; por lo cual, se definieron unas comisiones que se dedicaron a investigar y localizar estos terrenos o aquellos que tuvieran problemas jurídicos (Salas, P. A. 1998). En Bogotá, aparte de los barrios del sector El Codito, ${ }^{14}$ se encuentra el barrio Policarpa Salavarrieta como el referente más utilizado para ejemplificar el trabajo de la Central.

La defensa evidenciada en el barrio Policarpa sirvió como ejemplo para ser reproducido en los distintos frentes de resistencia y lucha, que se han venido gestando desde ese entonces.

La añoranza de ser propietario de un pedazo de tierra en el que las familias pudieran construir sus viviendas, educar sus hijos, verlos crecer y pasar los años de vejez en algo que fuera propio se percibía como un sueño inalcanzable, debido a las limitadas posibilidades económicas y financieras de la mayoría. Por ello, al escuchar sobre los terrenos que se invadían y de las posibilidades reales de conseguir algo propio, no dudaban ni un segundo en acercarse y averiguar sobre el proceso para adquirir un lote.

En ocasiones, no solo era la añoranza de tener algo propio, sino la reivindicación del derecho a vivir dignamente. Derecho lesionado por la falta de programas estatales que solucionaran la situación de vivienda para las familias de desplazados por la violencia y la pobreza rural. Asimismo, la consolidación del modelo capitalista en la ciudad de Bogotá produjo el incremento de mano de obra de bajo costo y de ejércitos de reserva para los procesos de expansión productiva.

La estrategia de toma de tierras consistía en que la Central conformaba un grupo que se encargaba de organizar a la población deseosa de adquirir su vivienda; de este modo, estas personas ayudaban a "organizar las casitas de cartón. Me acuerdo tanto que se hacía la casita de tres por tres o de tres por cuatro, más o menos, en un sitio cercano a la invasión y

14 Se tiene certeza que solo dos barrios del sector obedecieron a dinámicas distintas a la toma o recuperación de tierras; estos barrios son El Codito y Horizontes. Los demás barrios del sector estuvieron influenciados de manera directa o indirecta por Cenaprov, ya sea en la toma o en la incitación y defensa de la tierra. 
de ahí la llevaban y la colocaban en el lote ya armada, y se formaba de esta manera, la invasión de un momento a otro" (Lombana, 2011).

Así, la construcción espontánea de los barrios se consolidaba al aparecer, de un momento a otro, viviendas en un terreno que el día anterior parecía desocupado. Esta estrategia podía obedecer a una respuesta ante la eventual acción de los agentes policivos y militares del Estado, que debían actuar ante los emergentes procesos de invasión, recuperación o toma de tierras.

Es decir, existiendo la construcción asentada en el territorio, ahora ocupado y construido, se hacía más difícil la expulsión y consecuente demolición de las viviendas, pues aunque estas casas fueran construidas de un material no muy resistente, se requería otro tipo de maquinaria para su destrucción.

Por ello, había quienes asumían la confrontación directa y se enfrentaban al poder militar del Estado, mientras que otros, "aprovechando el bochinche", se apresuraban a terminar el traslado y la edificación de las viviendas (ibídem, 2011).

De igual forma, parte del problema actual que adolecen estos barrios es su preponderancia en la planeación estratégica para ocupar el territorio pero la carencia en planeación urbana; cuestión recurrente en los dictámenes de la tecnocracia estatal de carácter negativo para intervenir o prestar los diversos servicios públicos domiciliarios. Bien lo expresa uno de los líderes de las tomas de tierras de Cenaprov "yo sí sé que cuando estábamos (...) llevando las casitas allá y poniéndolas en posición, [era] en forma desorganizada, porque una invasión es así. A uno lo que le interesa es ubicar y después mira la organización y planifica, porque repito, el deseo es enorme de hacer la casita y colocarla. Eso hizo que se presentara cierta discusión entre los mismos invasores de querer fomentar la discordia por la ubicación" (ibídem).

Estas discordias no solo moldearon barrios con limitaciones en la accesibilidad y movilidad, sino que pudieron ser constructoras de una estratificación social al interior de estos territorios. Ya sea entre barrios, familias o vecinos. Esta estrategia no evitó la confrontación con las fuerzas estatales y en medio del jolgorio y la algarabía, la fuerza pública hacía presencia para 
desalojar a los nuevos ocupantes del territorio, utilizando cualquier medio. Este accionar, en la mayoría de los casos, producía confrontación directa mediada por la violencia entre los nuevos ocupantes, los organizadores de la toma y los agentes estatales ${ }^{15}$ (ibídem, 2011).

Actualmente, Cenaprov no solo asesora jurídicamente la escrituración y legalización de viviendas, también se dedica a la promoción y construcción de viviendas: "hemos tenido varias experiencias. Inicialmente, se ha comenzado por la compra de terrenos, la adecuación con las obras de urbanismo y la construcción por el sistema de autoconstrucción y de vivienda progresiva. En la actualidad ya tenemos la oportunidad de entregar multifamiliares, es un avance que Cenaprov no había explorado" (Lombana, 2012).

En conclusión, Cenaprov se ha consolidado como una organización que busca solucionar el problema del acceso a la vivienda, siguiendo, en la mayoría de los casos, la vía de la autogestión (ibídem, 2012). Por ello, los Planes de Ordenamiento Territorial, la exigencia de una reforma urbana integral y la lucha por la ciudad democrática e incluyente son las directrices que conducen el devenir de la organización (Valdivieso, 2011).

Las tomas de tierras más representativas y recordadas en el sector fueron las de los barrios Chaparral y Buenavista sectores I y II.

En efecto, el barrio Buenavista era un proyecto de construcción urbana que podría denominarse como multifamiliar y su planeación se ubica en el año 1954. Sin embargo, la posibilidad de construcción se vio afectada debido a que recayó sobre ella un embargo. Esto produjo que alrededor de 30 lotes fueran ocupados por sus compradores, asentándose en el territorio de acuerdo a las diferentes manzanas que componían el proyecto de la urbanización (Ángel \& Leguizamón, 1999).

El resto del terreno que no fue ocupado, lo compró una persona que dispuso el uso del suelo al cultivo de: maíz, arveja, calabazas y hortalizas; en otro sector del mismo terreno se cuidaban vacas, ovejas, gallinas, burros y

\footnotetext{
15 Se tiene conocimiento que para la defensa del barrio Policarpa se registraron seis muertos. No se tiene conocimiento si algo similar pudo haber pasado en El Codito.
} 
marranos. Esto último produjo la pérdida de los linderos y mojones de los lotes (ibídem, 1999).

Las personas interesadas en participar en el proceso de adquisición de una vivienda o un lote de Cenaprov debían participar en un curso de 20 horas. El curso tenía como objetivo dictar unos módulos sobre convivencia entre vecinos y solidaridad. Al finalizar las 20 horas, los participantes se hacían acreedores del carnet de afiliación a la organización (ibídem, 1999).

Otro requisito para asegurarse un lote en el sector era firmar y registrar un documento de arrendamiento, en el que se certificaba como arrendador a Provivienda. Según Ángel y Leguizamón (1999) el contenido del contrato era ficticio y se constituía como medio de protección de las familias ante la inquisición de las autoridades.

El proceso de invasión tenía distintas fases que buscaban evitar un posible desalojo por parte de las autoridades policivas y militares del Estado.

En una primera fase, las familias llegaban a unas casetas hechas con polisombra en las que se debía mantener las medidas de tres por tres metros y cumplir con algunas funciones de seguridad para evitar que personas ajenas a la organización se apropiaran de los terrenos o provocaran un incendio para llamar la atención de las autoridades distritales (ibídem).

La estrategia para cercar el lote consistía en que las primeras familias se debían instalar sobre sus límites; esto para proteger y controlar la invasión. Esta práctica se desarrolló hasta mayo de 1983, cuando al instalarse 150 familias alrededor del lote, se suspendió el ingreso de más familias (ibídem).

En el momento en el que se logró consolidar la invasión, Provivienda contrató el loteo, cuestión que se hizo con amplia dificultad dado que se habían consolidado vías vehiculares y peatonales. La asignación de lotes se realizaba por sorteo; claro está que las primeras diez familias que habían llegado al sector, se les permitió escoger su lote. De igual forma, aquellas que siendo residentes del sector estuvieran interesados en la asignación de un lote comercial, solo debían pagar $\$ 50000$ de más, los cuales podían pagarse por cuotas (ibídem).

La entrega se completaba con el pago de $\$ 200$. El primero de enero de 1984 se inició el proceso de entrega de lotes. La construcción de las vi- 
viendas estaba condicionada al pago de $\$ 700$ por el plano de construcción. No obstante, y como lo expresan Ángel y Leguizamón (1999), la mayoría de las personas hicieron caso omiso a los planos y construyeron de acuerdo a lo que mejor les parecía, siempre permaneciendo dentro de los límites de los lotes.

Según distintos relatos, el sentido comunitario se enarbolaba cuando algún vecino debía echar la plancha en la vivienda. Más bien, este suceso colectivo se convertía en una fiesta y no en una acción comunitaria.

Se hacía un comité de más de quince obreros a los cuales no se les pagaba, pero se les daba buena comida. Con quince o veinte días de anterioridad se ponía a fermentar la chicha. El día anterior varias vecinas se atareaban pelando un bulto de papa y condimentando la carne para el día siguiente [...] En el transcurso del trabajo se tomaba chicha y cerveza en abundancia. Claro que unos iban a trabajar y otros a tragar [...] En caso de faltar comida y bebida se iban y dejaban el trabajo tirado (ibídem, 1999, p. 95).

El otro actor externo que cumplió un papel protagónico pero menos espectacular que Cenaprov fue el Instituto de Misioneras Seculares (IMS). Este era un grupo de mujeres misioneras que se insertaron en la realidad del sector en el año de 1989 y que les permitió compartir la toma de lo que hoy es el barrio Chaparral.

Encontramos a la gente en esa lucha por su tierra, cosa que en ese momento era muy importante. Las recuperaciones de tierra nos llamaban la atención. iCómo la gente luchaba por defender sus derechos! Entonces eso también nos atrajo [...] Las mujeres eran las cabezas, las que habían luchado por la tierra, las que habían puesto el pecho a la policía. Y como nosotras también queríamos hacer un trabajo con mujeres populares entonces eso nos llamó mucho la atención (Alba, A. et al., 2007, p. 20).

En el momento en el que las misioneras se instalaron en el barrio Horizontes, comenzaron un trabajo principalmente con mujeres; realizaron 
acompañamiento a las familias, promovieron la generación de herramientas solidarias para la subsistencia, facilitaron la apertura de espacios para educación informal: dictaron cursos de sexualidad y planificación familiar, confecciones y peluquería (Alba, A. et al., 2007, p. 21).

El trabajo realizado por estos dos actores fue determinante en la consolidación de varios barrios del sector. Para Alba (2007), barrios como El Codito y Horizontes se vieron influenciados por el componente religioso en la consolidación de elementos comunitarios, las formas de expresión y participación colectiva y las maneras de organización. Por el contrario, los barrios Chaparral y Buenavista sectores I y II tuvieron fuerte influencia de partidos y movimientos políticos de todas las tendencias.

Precisamente, el trabajo de estos dos actores tuvo su punto culmen en la consolidación del barrio Chaparral. A comienzos de los años ochenta una familia vigilaba el terreno que se convertiría en este barrio, aunque existía certeza del dueño del predio, se comenzó el poblamiento de los terrenos deshabitados con la avenencia de la familia que los cuidaba. Para 1984, había unas diez familias asentadas en este territorio (Alfonso, O., Noriko, A. \& Jaramillo, A., 1997).

En esa época aparece un primer reclamo sobre la propiedad. Ante este hecho los ocupantes buscaron la ayuda de Provivienda. La respuesta de la Central fue de apoyo, por lo cual se decide la extensión del asentamiento y la organización de la junta de Provivienda en el barrio. Al finalizar el año 1985, el número de familias ascendía a 86.

La mayoría de los primeros ocupantes eran desplazados por la violencia del municipio de Chaparral, Tolima. Por ello el nombre del barrio. Los terrenos se tomaron aún con varios intentos de la fuerza pública por desalojarlos y en otros intentos, cuando las familias ya se habían instalado, fueron rechazados por los pobladores del barrio junto a Provivienda y otras organizaciones viviendistas.

La historia de Chaparral fue una continuación del proceso que ya tenía iniciado Provivienda con los barrios Buenavista — sectores I y II—y que sirvieron para consolidar la presencia de la Central de Vivienda en el sector.

En el año de 1992, las hermanas del Instituto de Misioneras Seculares se trasladaron a vivir al barrio Horizontes que ya se había conformado y 
se dieron a la tarea de seguir organizando grupos comunitarios, la idea era trabajar con la población más vulnerable del sector que para entonces eran los recién instalados habitantes de Chaparral.

El trabajo en este último barrio consistió en hacer acompañamiento a las familias y generar mecanismos solidarios de subsistencia y educación informal.

No obstante, el trabajo sufrió de un sinnúmero de dificultades, principalmente por las confrontaciones con Provivienda como ala social del Partido Comunista Colombiano. Esta presencia de partidos políticos tradicionales y de izquierda supuso un conflicto por el control de la población, quien alimentaría los cuadros clientelistas de los políticos personalistastradicionales, y por el control sobre los bienes y recursos públicos (Alba, et al., 2007).

Precisamente, la escalada de violencia que rodeaba la década de 1980 al país, la descomposición política, económica y social, las pujas político partidistas, la corrupción reinante a nivel social y estatal y la clandestinidad obliterada de la izquierda colombiana tuvieron repercusiones directas en las diferentes regiones y localidades, de las cuales El Codito no fue la excepción. Así, Cenaprov y el grupo de misioneras se vieron envueltos en una dinámica de confrontación y choque en los albores del cambio constitucional de 1991. Esta confrontación tuvo sus orígenes en la ruptura social impuesta por la realidad política. Así fue como el barrio se encontraba dividido en dos bandos.

Por una parte, las (personas) que pertenecían a la Junta de Acción Comunal y por otro lado, las que eran militantes de la Central Provivienda [...] Un grupo de personas hizo contacto con las JAC de barrios vecinos como: Horizontes, El Codito, San Antonio, Verbenal. Ellos y ellas les ofrecieron su apoyo poniéndolos en contacto con el concejal Jorge $\mathrm{Mu}$ ñoz Pinzón. Con su ayuda se conformó un comité pro-junta encargado de la conformación de la JAC. Cuando los comunistas y su junta directiva se enteraron de eso se formó la de Troya y empezaron las agresiones verbales y los insultos por parlante (Alba, et al., 2007, p. 27). 
Las manifestaciones violentas e insultantes se presentaban de diversas formas, con frecuencia se utilizaba el escenario de la asamblea general para persuadir a la comunidad de desistir de la idea de establecer la JAC, asî como para convocar a los habitantes para resistir ante la llegada de políticos oportunistas.

Algunos relatos implican la consecución de espacios comunitarios a la relación que se tenía con políticos tradicionales. Alba (2007) señala la gestión que realizó Hernando Durán Dusán, quien fuera jefe político del partido Liberal y alcalde mayor de Bogotá entre 1978-1982, para que se firmara un convenio con el Centro Comunitario Simón Bolívar Servitá para el funcionamiento de la Casa Vecinal Horizontes.

Así, se puede argumentar que la lucha en el sector no se limitó al acceso de la vivienda; según algunos relatos, los espacios comunales también fueron fruto de la confrontación directa con los agentes del Estado.

Un ejemplo de esta defensa por los espacios comunales fue el caso del barrio Horizontes:

(...) la comunidad vio la necesidad de conseguir un espacio donde reunirse, es por eso que, liderados por la Junta de Acción Comunal, 90 familias se organizaron y se tomaron el 20 de julio de 1980 el lote para el salón comunal [...] la cita fue a las cuatro de la mañana y cada uno llevaba lo que podía: la Junta recogió una cuota para comprar la tela asfáltica y unos palos, se montó como un cabildo y la consigna era que de ahí no nos movían (Gualteros \& Londoño, 2006, p. 11).

Otro ejemplo significativo fue la toma del lote del colegio Nuevo Horizontes (Sede C), que contó con la participación de un sinnúmero de mujeres, niños y niñas, lo que logró la entrega del lote a la comunidad por parte del dueño (señor Cristancho).

Un espacio de grata recordación para los habitantes de los barrios El Codito y Horizontes fue la apropiación del lote en el que actualmente está construida la Casa Vecinal Horizontes. Esta Casa nace de la necesidad de establecer un sitio donde los padres y madres de familia, en momentos de jornada laboral, pudieran dejar sus hijos e hijas al cuidado de adultos 
responsables. El proceso de construcción de la Casa Vecinal implicó una negociación con entidades locales para acceder al terreno y la unidad de los habitantes del sector.

El sentido comunitario se evidenció en la labor que la Junta de Acción Comunal y los padres y madres interesados cumplieron:

[Ellos] compraron la casa prefabricada [...] La comunidad se dio a la tarea de sacar tierra para poder construir lo que es hoy el jardín. Las madres usuarias teníamos un día de trabajo voluntario obligatorio. Empezamos a trabajar en los estatutos y a hacer las vueltas respectivas. Estábamos pasando por una etapa muy importante donde entidades y personas querían colaborar (Alba, et al., 2007, p. 24).

Del mismo modo, los habitantes de los barrios de la parte baja del sector tuvieron que recurrir a soluciones comunitarias para solventar la carencia de instituciones educativas o la imposibilidad de inscribir a sus hijos e hijas en las instituciones de esta zona de Usaquén.

Sobre este último aspecto, se resalta que en los colegios de la parte baja de la séptima se rehusaban a recibir estudiantes de los barrios colindantes situados en la zona montañosa. La explicación proviene de la percepción e influencia de los vecinos del colegio quienes señalaban a los habitantes de los cerros como "invasores, comunistas, roñosos y patirrajados" (Ángel \& Leguizamón, 1999, p. 105).

Así, y ante la negativa de los otros padres y madres de familia y rectores de los colegios de Tibabitá — barrio en el que se situaban los colegios más cercanos a El Codito-, los habitantes del sector tuvieron que construir una escuela en el barrio. "Aportamos una cuota por familia y con otras actividades realizadas levantamos un aula. Solo se dictaba primero de primaria y los padres de familia pagábamos el sueldo de la profesora" (ibídem, p. 114).

Con el paso de los años, la Secretaría de Educación de Bogotá construyó una escuela que recibe alumnos desde transición hasta quinto de primaria y la sede de bachillerato, que se ubica en el mismo lugar donde se construyó el aula por parte de los residentes del sector, prepara a los futuros bachilleres en doble jornada. 
Aparte de estos casos, existen otros dos colegios distritales en el sector: el colegio Don Bosco III y el Friedrich Naumann. También se destaca la iniciativa privada del colegio anexo Santa Francisca Romana.

\section{Las primeras demandas: los servicios públicos}

En un primer momento y con la llegada de algunos pobladores, el acceso a los servicios públicos fue disímil; por un lado, los primeros habitantes de algunos barrios contaron con la fortuna del recurso natural o con la ayuda de algún vecino quien les facilitó el acceso al agua.

Este fue el caso del barrio El Codito que con la llegada de los primeros habitantes, el propietario de la finca vecina Carlos Medellín, quien era magistrado de la Corte Suprema de Justicia y cuyo deceso se produjo en la toma al Palacio de Justicia, hizo instalar la conexión de agua en las siete primeras viviendas precursoras del barrio (Gualteros \& Londoño, 2006).

Del mismo modo, los habitantes del sector contaron con aliados que facilitaron la gestión de servicios públicos para el sector. En el caso del acueducto,

(...) en marzo de 1982, el director de "urbanizaciones intervenidas" del Instituto de Crédito Territorial informa al Club Rotario que con la ayuda del Club y la acción Comunal han implantado en el barrio Horizontes la instalación de las líneas de agua con sus correspondientes motobombas y cuatro piletas. Para esa misma fecha se dio la primera cuota para la instalación eléctrica y el 16 de mayo de 1983, el Club Rotario nos dota al comité local de salud y al puesto de primeros auxilios de la Cruz Roja con los elementos necesarios para prestar un mejor servicio (ibídem, p. 25).

No obstante, otros habitantes no tuvieron la misma suerte. Los tomadores de tierra de Buenavista recién llegados al sector, buscaron el apoyo de los residentes de la antigua urbanización, cuyo asentamiento había sido construido en años anteriores a la ola de invasiones de Provivienda, para acceder al servicio del agua. Esta urbanización contaba con un tanque de 
almacenamiento de agua. Ángel y Leguizamón (1999, p. 87) recuerdan esta situación:

(...) fuimos allí para que nos vendieran un poco de agua, pero cual sería nuestra sorpresa, cuando una señora que nos atendió nos gritó: "iInvasores, ladrones, quién sabe qué clase de plaga serán o de dónde vendrán!" Edelmira, una señora que llegó antes que nosotros a la urbanización nos dijo: "no se metan con esa vieja que es muy mierda y no sirve para nada. Aquí el agua toca traerla de debajo de la séptima, vengan yo les presto un garrafón. Toca que compren sus garrafones, para que la traigan”.

Este corto relato demuestra las dificultades en la consolidación del sentir solidario y comunitario, a pesar de que los habitantes podían compartir elementos definitorios en la construcción del territorio.

Lo mismo ocurrió con los nuevos barrios, como el caso de Chaparral que en el año de 1986 los habitantes del barrio tuvieron que comprar un tanque de almacenamiento de agua, muy seguramente debido a las diferencias existentes con los habitantes de los otros barrios, teniendo que acordar con la empresa de acueducto y alcantarillado la provisión de agua por medio de carrotanques. Para que el servicio se prestara sin contratiempos, la comunidad se organizó para construir cuatro baños.

Esto demuestra las dificultades que los pobladores encontraron para generar lazos de solidaridad entre los vecinos de los distintos barrios, si se entiende que, en ocasiones, estos no superan la extensión de dos manzanas.

Además, se evidencian las fracturas en la construcción del capital social con las percepciones divisorias en cuanto a los derechos de dominio sobre los lotes y las viviendas. Así, "los barrios [...] como El Codito y Horizontes poseían sistema de bombeo y distribución en pilas, pero el problema era que nos discriminaban demasiado y no nos permitían tomar el líquido, porque decían que éramos unos invasores, comunistas y patirrajados" (ibídem, p. 105).

A pesar de que existían quebradas en las inmediaciones de los barrios del sector, estas solo servían como fuentes del recurso para algunos barrios. Este es el caso de la quebrada Sarauz que para Ángel y Leguizamón (1999) 
era acaparada por los habitantes del barrio El Codito. "Por allí ni nos asomábamos, porque nos corrían a piedra" (p. 106).

Otra de las quebradas que proveía de agua al sector era la Inmaculada; esta quedaba ubicada en la finca de la Matucana, parte alta del sector, ofrecía la facilidad de acceder al recurso natural del agua pero dificultaba el transporte del mismo.

Cobra vital importancia el transporte que prestaba servicio a las canteras del sector ya que se convirtieron en proveedores de los habitantes para descender de la Matucana con los bidones de agua. Esta situación generó acercamientos entre los volqueteros y los habitantes de El Codito y se estrecharon los vínculos de amistad y sentimentales (ibídem). No obstante, aquellos pobladores que no contaban con facilidades para subir hasta la Matucana, se veían obligados a bajar al barrio Tibabitá, lo que implicaba recorrer una distancia considerable y enfrentarse a una población que no contaba con los afectos ni elementos solidarios necesarios para compartir el vital líquido. De hecho, la fuente de Tibabitá duró poco dado a que los vecinos de ese barrio no permitieron que los habitantes del cerro tomaran el agua de allí (ibídem).

Con el paso de los años, los habitantes del sector comenzaron a idear otros medios más acordes con los tiempos para acceder al agua. Fue así como en 1984 los habitantes de Buenavista acordaron construir un acueducto, utilizando un tanque viejo que existía en la parte alta del barrio y con la consecuente inversión de las empresas de Acueducto y Alcantarillado y de Energía Eléctrica de Bogotá. Sin embargo, esta solución fue temporal debido a que las motobombas instaladas no daban abasto para la cantidad de demandantes y a que al cabo de un tiempo se las robaron (Ángel \& Leguizamón, 1999).

Con estas dificultades se tuvo que ingeniar un mecanismo que permitiera el acceso al agua de forma segura para todos. Por ello se hizo necesario racionar la prestación del servicio de agua al horario de cinco a siete de la mañana y la presentación de un carnet para controlar que todos tuvieran garantizado su derecho a este líquido (ibídem).

Esta nueva situación generó mayores conflictos ya que la mayoría de los pobladores se negaron a pagar la cuota de mantenimiento (fue ne- 
cesario contratar a un fontanero para evitar el daño progresivo de las motobombas); esos enfrentamientos produjeron la renuencia de las empresas de Acueducto y Alcantarillado y de Energía Eléctrica a seguir prestando el servicio (ibídem).

Durante el tiempo sin servicio de acueducto se utilizó el sistema de carrotanques enviados por la Empresa de Acueducto, para suplir esta necesidad. En 1987, la construcción definitiva del acueducto y del alcantarillado fue una realidad como consecuencia de la gestión de un concejal liberal, dos concejales con filiaciones de izquierda y un conservador (ibídem).

La evolución de la prestación de otros servicios públicos fue parecida a la del agua pero sin escenarios dramáticos. El servicio de energía eléctrica era tomado de forma ilegal desde la avenida séptima, lo cual generaba ciertos enfrentamientos con los residentes de barrios legalizados, quienes denunciaban la acción de robo a la policía (ibídem).

Pero los grandes contratiempos se produjeron cuando los residentes, en busca de mejorar la calidad de luz que recibían, comenzaron a conectarse directamente en las líneas principales que pasaban sobre la séptima. Estos conflictos fueron consecuencia de tomar la luz del cable que se conectaba a la línea principal. "Lo que se convirtió en un contrabando al contrabando" (ibídem, p. 110).

Igual que el acueducto y el alcantarillado, la Empresa de Energía Eléctrica comenzó la construcción de sus redes en el año 1987.

Para cocinar, los hogares utilizaban cocinol: este es un derivado del petróleo que se destina al consumo doméstico, su composición y textura se parece al de la gasolina pero se diferencia en su nivel de octanaje. Para adquirir el cocinol, las familias debían estar inscritas en los barrios que habitaban y, en el momento de compra, debían presentar el carnet que acreditaba su residencia y facilitaba el control sobre la provisión del combustible (ibídem).

Por el estado germinal de estos barrios, sus habitantes no contaban con los recursos necesarios para el almacenamiento y distribución de este combustible; por ello, debían recurrir a otros barrios para comprarlo. Sin embargo, las dificultades para conseguir un carnet y el preciado combustible en otro barrio fueron determinantes para que se gestara en el interior de la 
junta directiva la iniciativa de comprar un tanque de almacenamiento; la adquisición de un tanque viejo se hizo posible, pero nunca llegó el cocinol al sector (ibídem). Años después fue reemplazado por gas propano, lo que facilitó la cocción de alimentos y prescindió de la generación de demandas colectivas.

En cuanto a la instalación de las líneas telefónicas, se presentó una situación que terminó por favorecer a un grupo de personas cuyos afectos eran cercanos a Provivienda. Según lo relata Ángel y Leguizamón (1999, p. 113), “en 1991 Clara López Obregón, quien era alta funcionaria de la ETB y muy amiga del concejal Carlos Romero, consiguió que por la vía principal se instalara un tramo de red con capacidad para trescientas líneas. Esta red terminaba exactamente al pie de la oficina de la junta directiva y los únicos beneficiados fueron sus seguidores".

Este hecho fue causa de un rechazo generalizado de las JAC de Buenavista y Estrellita del Norte, que con la ayuda del concejal Jorge Muñoz, se reclamó vehementemente ante el gerente de la ETB. Un año después de la reclamación se instalaron las redes faltantes para aquellos hogares que así lo reclamaban (ibídem).

\section{A modo de conclusión. Nuevas y antiguas demandas: derechos reales, basuras e infraestructura}

Luego del recorrido realizado por la forma como se asentó la población en el sector y de presentar las luchas sociales por el derecho a la vivienda digna y el acceso a los servicios públicos, queda por señalar algunas situaciones actuales que tienen conexión directa con la ocupación histórica del territorio.

\section{Derechos reales: los procesos de escrituración y la legalidad de los barrios}

Como consecuencia del poblamiento del sector, un factor que ha marcado la personalidad de los habitantes de El Codito ha sido su renuencia a desalojar 
el territorio que habitan. En un buen número de ocasiones y bajo la argumentación técnica aunque no coherente ni consolidada de los gobiernos de la ciudad, se ha pretendido reubicar a los pobladores de estos barrios.

Lo que algunos diagnósticos estatales señalan es que debido a los procesos de autoconstrucción de las viviendas, la carencia en el seguimiento a las normas de construcción y a que el terreno sobre el que se asienta el sector fue zona de remoción en masa o de explotación de canteras, por preservar el derecho a la vida de los habitantes, se debe reubicar a un número indeterminado de personas.

Esta dificultad territorial sobre El Codito ha perpetuado una relación distante entre los habitantes del sector y las autoridades locales, especialmente los representantes directos de la Alcaldía Mayor de Bogotá, dado a que en reiteradas ocasiones se expresa la necesidad de iniciar un proceso de reubicación del sector.

Esta relación se profundiza ante la negativa o la imposibilidad de legalizar barrios sobre terrenos no aptos para la habitabilidad o subsistencia, cuestión que en reiteradas situaciones se debate al interior de los espacios comunitarios como respuesta a las demandas de los pobladores del sector.

Al mismo tiempo, los procesos de escrituración de las viviendas, especialmente de aquellas que hicieron parte de los procesos de autoconstrucción y toma de tierras, son dispendiosos en tiempos y recursos económicos. A pesar de que en algunos casos Provivienda continúa su labor en el sector sobre este tema, existen algunos abogados cuyas prácticas poco profesionales ayudan a perpetuar la situación incierta sobre la propiedad de los bienes ocupados.

Por si fuera poco, y ante la normatividad expuesta anteriormente y el vacío jurídico que existe sobre el tema, la incertidumbre se posa sobre los habitantes del sector al entender la imposibilidad administrativa existente para declarar la propiedad sobre estos bienes. El hecho que no se defina el límite de la reserva forestal sobre los cerros orientales de la ciudad es un impedimento para cualquier autoridad decidir sobre las personas y los bienes que actualmente se asientan sobre ellos. 


\section{Basuras e infraestructura}

Ahora bien, en los relatos y discursos de diferentes líderes y habitantes del sector, los temas de infraestructura y aseo cobran especial importancia en el momento de señalar los principales problemas de los barrios de El Codito ${ }^{16}$ (Mendoza \& Guevara, 2012, p. 224).

Así, lo que se observa es el problema de basuras e infraestructura cuya relación puede tener vínculo directo con la forma como estos barrios se han ido construyendo con el paso del tiempo.

Los problemas actuales relacionados con la infraestructura del sector se pueden señalar en: el mantenimiento de la malla vial; el acceso efectivo a los servicios públicos domiciliarios; la adecuación de los espacios públicos, especial atención deben tener los parques del sector; la adaptación de las escaleras y el mantenimiento de las existentes; así como la formulación de políticas y proyectos que permitan la verdadera inclusión espacial de los adultos mayores y de las personas en condición de discapacidad.

A pesar de que el sector se consolidó como una expansión de la ciudad reticular — modelo de ciudad que se expande en derredor de las avenidas principales de la ciudad_- las vías que comunican los barrios del sector con la ciudad no presentan un buen estado. A pesar de que se está realizando desde al año 2009 la construcción de la vía principal del sector, que para los propósitos expansivos de la ciudad facilita el transporte de los municipios orientales de Cundinamarca; no obstante, esta obra no permitirá el tráfico pesado que se proyecta con la realización del Plan Zonal de Expansión Norte, cuestión limitada por el espacio reducido existente entre los barrios que rodean la vía.

No obstante, el sector se ve beneficiado por la instalación de nuevas redes telefónicas y de acueducto y alcantarillado, con lo que se espera que se legalice la situación de muchos habitantes del sector, por lo menos en el tema de servicios públicos.

16 Se exceptúan los fenómenos de inseguridad reseñados en Mendoza y Guevara (2012) ya que estos no corresponden a la relación directa con el poblamiento del sector, sino a fenómenos que, en ocasiones, desbordan la propia esfera de la ciudad. 
Ahora bien, un elemento que dificulta la intervención en el tema de basuras y de infraestructura son las características propias del terreno en ladera. Estas condiciones determinan las dificultades para la movilidad, la planeación y el diseño de las vías, calles, andenes y escaleras.

Aunque este es un elemento a tener en cuenta, no se puede convertir en una excusa para la falta de coordinación y efectividad por parte de las instituciones estatales, las empresas prestadoras de servicios públicos y los pobladores del sector.

Especial mención se hace sobre estos últimos y sus representantes, como las JAC, ya que sobre ellos recae el proceso de desarrollo, por eso llama especial atención el hecho que estas ya no tienen el mismo compromiso y credibilidad, en parte debido a que las necesidades y los problemas no son los mismos que en los primeros años de los barrios y a que los líderes en las JAC no han hecho las mejores administraciones ni gestiones (Gualteros \& Londoño, 2006).

No se debe dejar de resaltar que la coyuntura sistémica debilita las visiones y los ánimos de las comunidades y actores sociales, para afrontar la realidad que se antepone a los ojos citadinos. Así como la evidencia del desgaste de los movimientos sociales en épocas neoliberales.

Nuestro contexto actual es de fragmentación territorial, económica, social, cultural y política. Este nuevo tiempo está marcado por el sentimiento de la crisis y la impotencia. Las formas de organización social anteriores ya no logran ser vehículos de expresión colectiva y autónoma de la población. Se trata de una crisis de sentido que toca las formas fundamentales de socialización. El ambiente general es de incertidumbre (Alba, A. et al., 2007, pp. 17-18).

Por ello la importancia de estudiar el territorio pero como forma de expresión de la comunidad, pues sin ella, las complejidades del desarrollo se acrecientan y se desplazan a la esfera del individuo. 


\section{Bibliografía}

Alba, A., Gualteros, E., Jiménez, C. \& Rodríguez, A. (2007). Sistematización de la experiencia de participación de la cooperativa Copevisa en la localidad de Usaquén (Bogotá, Colombia). Recuperado de www.alboan.org/archivos/595.pdf

Alcaldía Mayor de Bogotá. Departamento Administrativo de Acción Comunal. (1998). Bogotá, historia común. Trabajos ganadores segundo concurso de historias barriales y veredales. Bogotá: IDCT.

Alcaldía Mayor de Bogotá. (2006). Plan de Manejo Ambiental-Audiencia CAR. Bogotá: Autor.

Alfonso, O. Noriko, A. \& Jaramillo, A. (1997). Organización popular y Desarrollo urbano en Bogotá. Santafé de Bogotá: Universidad Externado de Colombia. Facultad de Economía.

Angel, L. \& Leguizamón, P. (1999). El ayer y hoy de Buenavista. En: González, B. Bogotá, historia común. Tomo III (pp. 78-129). Bogotá: Departamento Administrativo de Acción Comunal y Alcaldía Mayor de Santafé de Bogotá

Arango, C. (1981). Crónicas de la lucha por la vivienda en Colombia. Bogotá: Editorial Colombia Nueva.

Archila, M, Álvaro, D., García, M \& Prada, E. (2002). 25 años de luchas sociales en Colombia. 1975-2000. Bogotá: Centro de Investigación y Educación Popular (Cinep).

Bohórquez, I. A. (2008). La política pública para los cerros orientales de Bogotá. Territorios, (18-19), pp. 229-242.

Camargo, G. (2001). El proceso histórico y las perspectivas de ordenamiento de los cerros orientales de Bogotá D. C. Ambiente y Desarrollo, (9), pp. 119-136.

Camargo, G. (s. f.). Marco normativo de los Cerros Orientales de Bogotá. Recuperado de http://www.cerrosdebogota.org/joomla/images/stories/Historia/ marconormativo.pdf

Camargo, G. (s. f.). Historia pintoresca y las perspectivas de ordenamiento de los cerros orientales de Santa Fe de Bogotá. Recuperado de: http://www.cerrosdebogota.org/joomla/images/stories/Historia/historiacerrosdebogota.pdf 
Camargo, G. (2006) Una norma que nos permita ayudar a conservar los cerros orientales. Recuperado de: http://www.rds.org.co/aa/img_upload/aea709feb9d6e6499a219fa83c2c5451/Cerros_orientales.pdf

Ceballos, R. \& Olga, L. (2005). Vivienda social en Colombia. Una mirada desde su legislación 1918-2005 (1 $1^{a}$ ed.). Bogotá: Editorial Javeriana.

Central Nacional Provivienda. (1981). La unidad de acción y las organizaciones populares de vivienda. La vivienda popular hoy en Colombia (pp. 283294). Bogotá: Centro de Investigación y Educación Popular (Cinep), Foro Nacional por Colombia.

Congreso de la República de Colombia (1968). Ley 66 de 1968 "Por el cual se regulan las actividades de urbanización, construcción y crédito para la adquisición de viviendas y se determina su inspección y vigilancia”. Corporación Autónoma Regional de Cundinamarca-CAR (2006). Plan manejo de la reserva forestal protectora bosque oriental de Bogotá. (Documento técnico). Recuperado de http://www.car.gov.co/?idcategoria $=3812$

Diaz, L. (s. f.) Cerros de Bogotá iun espacio (e) en vía de extinción? Recuperado de http://chapineroverde.org/biblioteca/CERROS_ORIENTALES_CINEP.PDF

En El Codito los buenos somos más. (s. f.). En Periódico El Tiempo. Recuperado de http:/www.eltiempo.com/archivo/documento/CMS-10218044

Gualteros, S. \& Londoño, J. (2006). Caracterización de la unidad de planeación zonal (UPZ) Verbenal. Diplomado en control social. Bogotá.

Guillén, F. (1979). El poder político en Colombia. Bogotá: Punta de lanza.

Lombana, N. (2011). Barrio Policarpa Salavarrieta: 50 años de lucha, resistencia y dignidad. Recuperadado de http://www.pacocol.org/index. php?option $=$ com_content $\&$ task $=$ view $\&$ id $=7751$

Lombana, N. (2012). Cenaprov sí les cumple a los destechados colombianos. Recuperado de http://www.pacocol.org/index.php?option=com content\&task $=$ view \&id $=11990$

Mendoza, M. \& Guevara, J. (2012). Retos y avances de desarrollo local. Caso El Codito. Bogotá: Editorial Universidad del Rosario.

Mesa Ambiental de Cerros Orientales. (2008). Territorios Populares, Ambiente y Hábitat. Bogotá: Ediciones Gente Nueva.

Partido Comunista Colombiano (PCC). (2008). Historia del PCC 1930-2008 78 años de lucha. Recuperado de http://www.pacocol.org/index.php?option=com content\&task $=$ view $\&$ id $=334$ 
Personería de Bogotá. (2007). Cerros orientales. Desafío institucional. (Documento institucional). Bogotá.

Presidente de la República de Colombia. (1977). Resolución 0076 de 1977. "Por la cual se aprueba un Acuerdo de la Junta Directiva del Instituto Nacional de los Recursos Naturales Renovables y del Ambiente - Inderena-". Bogotá.

Primer inventario del D. E. 298 barrios fuera de Ley. (1975). El Tiempo, p. 7A.

Ramírez, J., Useche, I., Jiménez, F., Soto, P., Giraldo, F., Molina, H. et al. (1981). La vivienda popular hoy en Colombia. Bogotá: Centro de Investigación y Educación Popular (Cinep), Foro Nacional por Colombia.

Salas, P. A. (1998). Policarpa. En una noche amanecía un barrio. En: Salas, P. A. et al. Bogotá, historia común. Tomo II (pp. 19-94). Bogotá: Departamento Administrativo de Acción Comunal y Alcaldía Mayor de Santafé de Bogotá.

Torres, A. (2003). La ciudad en la sombra. Barrios y luchas populares en Bogotá. 1950-1977. Bogotá: Cinep.

Torres, A. (2007). Identidad y política de la acción colectiva. Organizaciones populares y luchas urbanas en Bogotá. 1980-2000. Bogotá: Universidad Pedagógica Nacional. (Colección Ciencias Sociales).

Torres, A., Mendoza, N., Barragán, D., Vargas, A., González, M., Avendaño, M. et al. (2003). Organizaciones populares, identidades colectivas y ciudadanía en Bogotá. Bogotá: Universidad Pedagógica Nacional. División de Gestión de Proyectos CiUP. Facultad de Humanidades, Departamento de Ciencias Sociales.

Torres, C. (2009). Ciudad informal colombiana. Barrios construidos por la gente. Bogotá: Universidad Nacional de Colombia. Sede Bogotá. Facultad de Artes. Maestría en Hábitat.

Torres Tovar, C. A. (2000). La ciudad, espacio de inclusión y exclusión. La ciudad: hábitat de diversidad y complejidad (pp. 318-332). Bogotá: Facultad de Artes. Universidad Nacional de Colombia.

Valdivieso, A. (2011). Con rotundo éxito se realizó la XxXI Asamblea nacional de Cenaprov. http://www.pacocol.org/index.php?option=com_ contentËtask $=$ view $\mathcal{E} i d=8553$

Zambrano, F., Castelblanco, C., Sánchez, L., Hoyos, J., Benninghoff, F., \& Ruíz, M. (2002). Comunidades y territorios. Reconstrucción histórica de Usaquén. Bogotá, Colombia: Panamericana. 